\title{
Introducing a Computer-assisted Method for Teaching Summarizing Skills to EIL/EFL Students
}

\author{
Robert G. Lantin \\ Department of English, Aletheia University \\ 32, Jen Li Street, Tamsui, New Taipei City
}

Taiwan 251

E-mail: robertlantin@temple.edu

Received: November 11, 2017 Accepted: November 26, 2017 Published: November 28, 2017

doi:10.5296/ijele.v6i1.12202 URL: https://doi.org/10.5296/ijele.v6i1.12202

\begin{abstract}
The paper introduces a computer-assisted method for teaching summarizing skills to EIL/EFL students - the Event Ordering method, or EVO for short. EVO, I shall contend, helps students develop basic reasoning skills. To support this claim, I argue that over time, EVO introduces a recurrent 'loop' process whereby readers become increasingly adept at projecting logical relations between events as they read, thus enabling them to foresee and make informed guesses as to which events from a narrative - typically from graded readers-would most likely find their way into the summary. This, I shall further argue, has two significant consequences: (i) it helps students build organizational skills - for being able to detect and make logical connections between important events is precisely what summarizing asks of readers; and (ii) it helps students become better readers. In the first section of the paper, I introduce the various theoretical aspects of EVO; I then move on, in section two, to support EVO with several samples of student writing.
\end{abstract}

Keywords: Summarizing skills, Event Ordering Method (EVO), EIL/EFL, Comprehensible/Comprehended Input 


\section{MlMacrothink}

\section{Theoretical Foundation}

\subsection{Introduction}

Summarizing is an essential academic writing skill. Anyone with a graduate degree in just about any discipline knows how to summarize books and articles. Undergraduate term papers also presuppose the ability to summarize. Although mainly used as an intermediary between reading and research writing, summarizing can also function as an independent form of writing. ${ }^{i}$ As such, summarizing can indeed be taught in a reading/writing class. In either case, summarizing is always a derivative form of writing-it originates from a prior (text-based) source. ${ }^{\text {ii }}$ In this context, summarizing can be broadly understood as a higher-order skill — a cognitive ability that can be applied to other cognitive and motor skills. In this sense, summarizing in many ways resembles other practical skills. ${ }^{\text {iii }}$

This paper will propose a method for teaching summarizing skills to learners of English as an International/Foreign Language (EIL/EFL).

\subsection{Learning to Summarize}

For EIL/EFL learners, the acquisition of summarizing skills presupposes a reasonably high level of comprehensible input in the L2 reading material. ${ }^{\text {iv }}$ In other words, students must understand the books they read prior to learning summarizing skills. This is crucial. In the present context, the requirement is met by introducing 'graded readers'-books specifically written to meet pre-established vocabulary, syntactic and morphological target levels of difficulty. Once reading levels are correctly set ${ }^{\mathrm{v}}$, students understand the books they read. This is an important pre-condition for building strong summarizing skills. It is also crucial for building confidence and maintaining a high level of motivation. ${ }^{\mathrm{vi}}$

Once students have found the right general reading level, they can start sampling books to fine-tune levels and make further micro-adjustments. As mentioned earlier, finding the right reading level is very important. After the optimum reading level is set, students can easily understand the books they read without systematically relying on dictionaries and/or translation. ${ }^{\text {vii }}$ At this early stage, students are encouraged to start by finding literary genres they like among the available titles and create lists of favorites. In the end, the use of graded readers and the freedom to choose material to their liking go a long way towards maintaining a high level of motivation.

\subsection{Event Ordering-EVO}

The instructor prepares lists of main events for each book that will be made available to the class. ${ }^{\text {vii }}$ The lists of main events are then used in the classroom. Each EVO exercise features a random list of anywhere from 6 to 10 key events taking place in a story. Before the exercise begins, the events are shuffled so they appear in random order. Students need to re-order the events chronologically to match the development of the story as it appears in the book. This is a crucial first step in the progressive acquisition of summarizing skills.

Several very important skills are acquired through EVO: first, students are effectively mentally re-mapping the development of the story each time they complete the exercise. The 
event ordering quiz indeed brings students to mentally follow through the main events of an entire story from beginning to end. I call this 're-mapping' simply because that's essentially what it does: it gives students means through which they can 'see' all the important developments found in the book in one crisp series of short sentences written in reported speech. Over time, the re-mapping exercise helps students develop their own sense of what important events to look for in a book.

Secondly, and as a corollary to re-mapping, students can then 'see' how the story is structured. More crucially, students are implicitly exposed to the logical relations that hold between events. It becomes clear, for instance, that a given event, A, could not have happened unless another event, B, had already happened prior to A. Or that, on the grounds of A's obtaining, other events, C, D, or E, could now happen. I call this the 'logical vista' of a narrative.

Thirdly, re-mapping and logical vista introduce the possibility of what I call 'the recurrence loop pattern'. Once this third feature of EVO comes into play, students start to 'project' logical inferences as they read, and this helps them visualize the story-give the story a 'place' in their own life narrative, the ongoing story of their life. ${ }^{\text {ix }}$ More practically, it enables them to foresee and make guesses as to which events from the story will likely find their way into the EVO quiz. It is precisely at this point that the summarizing skill settles in. Students are now ready to start writing their own summaries.

The recurrence loop pattern helps students predict event ordering questions. Given sufficient time and repetition, ${ }^{\mathrm{x}}$ the EVO task develops as a skill - or to use my terminology: re-mapping, logical vista and the recurrence loop help students build strong summarizing skills. The ingredients involved in the EVO task are useful for summarizing a story and outlining key points of its development. This, I claim, is a clear benefit of the EVO method.

\subsection{Reported Speech and Sequential Markers}

To facilitate the task of writing summaries, the instructor re-writes all the main events that make up the EVO exercises in the third person ('reported speech'). Students then need to learn how to use sequential markers ('first', 'next', 'then', 'after this', 'finally', 'in conclusion', etc.) to compose their summaries.

The use of reported speech and sequential markers is typically part of a special writing course taken in conjunction with a reading course. ${ }^{x i}$ Students learn to use sequential markers by following examples provided in class.

An example will show how the list of events is re-written. Here is a listing of some of the main events from a book titled Bad Company. ${ }^{\text {xii }}$ The events are re-written in reported speech:

The body of Claudia Engel is found near the Grand Hotel in Hythe.

DI Helen Shepherd asks DS Brian Webb to get a waiter at the Grand Hotel.

DS Brian Webb shows DI Helen Shepherd in the Wells room.

James McNab enters the Wells room. 


\section{Macrothink}

DI Helen Shepherd wants to know about a man who was in the bar the previous evening.

We learn that Harriet Johnson hated Claudia Engel.

We learn that Claudia Engel was good at her job.

We learn that James McNab and Claudia Engel were arguing the previous afternoon.

We learn that MMI is losing money.

DS Brian Webb and DI Helen Shepherd interview Darren Fleming.

We learn that Darren Fleming and Claudia Engel had studied together in London.

We learn that the key to Claudia Engel's hotel room has disappeared.

The police are looking for Claudia Engel's computer.

DI Helen Shepherd orders everyone to meet in the Wells room.

James McNab confesses to murdering Claudia Engel.

The list of events covers the entire story chronologically, and as such provides a good example of an instructor's preparation of the book's EVO template prior to being used in the classroom with students. Once the template is complete, it is ready to be randomly re-ordered in exercises given to students. The random re-ordering of events is important for student training. This amounts to the first of three phases, or sections used in the reading and summary writing courses - what I earlier called 're-mapping'.

\subsubsection{Phase One-Re-mapping}

Re-mapping is an exercise whereby students re-order the list of events to match the chronology found in the book. This is essentially a 'reading' exercise. Students read books and take EVO quizzes without having to write. In the re-mapping phase, students practice event recognition - the ability to recognize important events as they read. This phase necessitates a fair amount of reading until students reach a point at which they can 'see' important events as they read a book. EVO quizzes help infuse this ability in readers. ${ }^{\text {xii }}$

Keeping the same example, here is a possible EVO quiz given to readers of Bad Company:

Re-order the following events to match the order in which they appear in the book:

We learn that Claudia Engel was good at her job. (2)

We learn that James McNab and Claudia Engel were arguing the previous afternoon. (3)

The body of Claudia Engel is found near the Grand Hotel in Hythe. (1)

DS Brian Webb and DI Helen Shepherd interview Darren Fleming. (4)

James McNab confesses to murdering Claudia Engel. (7)

We learn that the key to Claudia Engel's hotel room has disappeared. (5) 
The police are looking for Claudia Engel's computer. (6)

In this example, the quiz-taker needs to follow the narrative's development to complete the task. The numbers in parentheses - included above for ease of exposition only-indicate that development. In an online version of the exercise, quiz-takers simply need the use the 'drag-and-drop' function to complete the task.

The important benefit of the re-mapping exercise is that over time, by repeating the task with each book they read, students start making informed guesses as to which events are more likely to occur later in the EVO exercise, based on what has already happened. In other words, students start making projections as they read. The ability to make projections is part of the other two phases mentioned earlier, which I call 'logical vista' and 'recurrence loop'.

\subsubsection{Phase Two-Logical Vista}

The expression 'logical vista' simply refers to the students' ability to recognize certain constraints that apply to relationships between events taking place in a story. The constraints follow logical necessity in very much the same way they do in real life. In our example of the narrative of Bad Company, Claudia Engel must die before the police investigation can get started: it would make no sense to investigate a death that has yet to occur. In much the same way, the cause of Engel's death must precede her actual dying; and once established, it may or may not rule out further investigation. Had Engel died at the end of a long battle with cancer, the narrative would more than likely have taken a different course. As it happens, a murder investigation is carried out by DI Shepherd and DS Webb. The reader is invited to follow their footsteps as the story develops, eventually leading them to the culprit. As a literary genre, murder mysteries are generally good at making explicit their use of logical relations between events in the development of a narrative; this helps students to recognize the ways in which important events are logically bound to one another.

\subsubsection{Phase Three-Recurrence Loop}

What I call the 'recurrence loop' comes from repeated reading. ${ }^{\text {xiv }}$ It brings together the key benefits of the previous two phases. Re-mapping and logical vista lead to a recognition of important events as they occur in a narrative. The ability to 'see' important events as they occur in a narrative is precisely what summarizing presupposes. Along with gains in the acquisition of vocabulary, syntax and morphology, this is possibly the most important ability and skill that reading can provide for students. By mere repeated and sustained reading, students become better at seeing important events as they read.

The EVO quizzes merely prepare students for this ability of foreseeing what will eventually find its way in a quiz. Once students have reached this point, they can start taking notes, in effect gathering the essential information that will later find its way in a written summary.

How long does it take to reach phase three ? That will depend on several factors, of course - but (1) the amount of time spent reading; (2) the number of books read; and (3) the frequency at which students read the books are very important. This is potentially where extensive reading (ER) pays dividends. The ability and the freedom to choose books that are 
both interesting and comprehensible are key factors. Motivation is essential.

\subsection{Comprehensible Input and Motivation}

The entire process described above works iff the students understand the books they read-ideally every word of each book. This is the Comprehensible Input claim that Steven Krashen introduced back in 1982. ${ }^{\mathrm{xv}}$ Furthermore, saying that readers must fully understand what they read is saying that the goal is $100 \%$ comprehensible input, with the end goal set to reach $100 \%$ comprehended input. That is a pre-requisite for acquisition, claims Krashen. ${ }^{\text {vi }}$

One important aspect of the EVO task mentioned above is that it should be relatively easy to successfully achieve for students who have read and understood the entire book. At the same time, the task must be such that anyone who has not read the entire book or who has not understood the story should more than likely fail. Hence the task can provide adequate control in the context of a reading/writing course. Teachers set goals that students then meet by reading books and completing tasks. This scheme works relatively well for motivated students. But as every teacher knows, college-level students often lack motivation. The summarizing task, with its relative easiness-students read books that they fully understand, so that tasks are easy to complete - has the potential to boost confidence and motivation.

The effect of success is experienced at the emotional level in everyone. Being successful at reading and summarizing thus creates a deep emotional effect that taints the whole being of the task-taker in an existential sort of way. Success breeds confidence and self-esteem. It tells a student "Hey, I can do this!". Eventually, instrumental motivation-meeting deadlines; reaching a word goal; passing a course; getting a higher grade; etc.- reaches deeper within a person and turns into intrinsic motivation. Once this is achieved, the entire book-reading/summarizing experience becomes something of a game. The ludic aspect of book-reading and summarizing kicks in, as it were, and the focal point of the entire process shifts from the book itself to the summarizing task and indeed the summary itself. Books are read more regularly and more swiftly at this point. Krashen's context of "low anxiety filters" has been reached. ${ }^{\text {xii }}$ Reading has become fun. Summarizing has become "second nature."

\subsection{How Can We Promote Low Anxiety Filters?}

Stephen Krashen asked that question decades ago. He spoke of "pressure-free environments" where acquisition of structure in the target language could take place. More recently, a lot of research findings in applied linguistics have built a strong case for "student-centered methods" in second/foreign language learning contexts. Researchers found that students who were more in control of the learning situation were more successful at language learning. ${ }^{\text {xiii }}$ In the reading classroom, students of Asian cultures-Taiwanese students in this specific instance - often complain of reading choices that are made for them. The reading material scheduled by the instructor is often considered "too boring" and, more likely than not, motivation quickly dwindles. It's in that context that the notion of student control should be understood here-namely, giving students significant control on what, where, and when they read. ${ }^{\text {xix }}$

This has the immediate consequence of taking most of the reading outside the classroom. 


\section{MInstitute ${ }^{\text {Mnk }}$}

Students now decide where to read. With correct reading levels established, students also decide what to read. With that freedom comes an absence of constraint on just when reading should be carried out. It is entirely left to the reader.

At the other end of the process, quiz-taking, as was briefly alluded to earlier, is itself entirely automated and constraint-free, insofar as an online quiz-bank is always accessible-24/7, from any computer or device that has online access, i.e. an internet connection. Students can travel anywhere in the world and still be able to read books (or e-books) and take quizzes. Hence, students also get to decide where and when to take quizzes. ${ }^{\mathrm{xx}}$ This freedom has the potential to create the pressure-free environments Krashen was describing.

\subsection{The Online Quiz Bank ${ }^{x x i}$}

The digital solution is an online quiz bank. It is the response to logistical problems teachers were facing while implementing the Extensive Reading method in their reading courses. ${ }^{\text {xii }}$ The idea behind an online quiz bank is quite simple: to create a dedicated quiz for large numbers of graded readers. ${ }^{\text {xiii }}$

Each quiz consists of 10 questions randomly chosen from a pool of between 50 and 75 questions. There are four different categories of questions: (i) multiple choice; (ii) true/false; (iii) who said; and (iv) event ordering. Usually, each of the first three categories comprises three questions, and the last question is reserved for EVO. To complete the EVO question, as we saw earlier, the student must read several short descriptions of key events taking place in the story, and re-arrange them in the same order they originally came in.

The quiz questions are deliberately kept at a general level so that students who have a fair understanding of the whole story should pass with relative ease. Detail retention is not necessary. This is in line with the goal of Extensive Reading, where quantity matters more than quality - acquisition of structure is a slow process, and sustained reading over long periods of time is thus crucial. ${ }^{\text {xxiv }}$

The question must now be asked: can the EVO method be successfully implemented? The next section will provide practical evidence that it indeed can be.

\section{Practical Application}

\subsection{The Group}

The EVO method was introduced to a group of 15 students registered in an English Composition course over two consecutive semesters. All the students were Freshman English majors at a Taiwanese university.

\subsection{Establishing the Reading Levels}

The reading level was established for each student after taking both the Shinshu and Paul Nation's VST tests. Both tests were deemed necessary to insure a fair assessment of syntax, morphology and vocabulary levels. 


\subsection{The Method}

Students were free to choose books corresponding to their respective reading level. Each student read one book each week prior to coming to class. At the beginning of each class, students took the MReader quiz for their book, focusing on the EVO question. They were asked to complete the EVO activity and write down the list of events as the answer to question 4 of the English Reading Exercise Form.

\subsection{The English Reading Exercise Form}

The form featured five entries, as follows: 1. What is the title of the book? / 2. Make a list of at least five new words you learned from this book. / 3. Name the main characters in the story. Which character is your favorite? Why? / 4. What is the story/subject of this book? Name all the main events in the story. / 5. Did you like this book? Explain why or why not.

Students read 18 books over a period of two semesters: 7 books in the first semester, and 11 in the second. They were asked to answer questions 1 to 4 in the first semester. The instructor spent a few weeks introducing students to the concepts of reported speech and sequential $\underline{\text { markers, }}$ as they would feature in all the students' answers to question 4. At the start of the second semester, students were introduced to the concept of subjective writing, as it would be used to answer question 5. The instructor emphasized the sharp difference between (1) summarizing as a form of objective writing - what happens in the story — and (2) describing one's feelings as a form of subjective writing - how one reacts to what happens in the story.

\subsection{Using Reported Speech and Sequential Markers}

At the beginning of the first semester, students learned about the need to use reported speech when writing summaries. They were also instructed on the need to use sequential markers in conjunction with reported speech when writing summaries. For the duration of the course, the lists of main events came from MReader quizzes prepared by the instructor, and students were given time to practice taking quizzes on the MReader website. Additionally, they were given the following lists of sequential markers:

2.5.1 For the beginning of the story:

In the beginning, ...

First, ...

At the start of the story, ...

The story begins with ...

2.5.2 Once you have introduced the first event, you continue with:

Then, ...

After that, ...

Next, ... 
Later, ...

2.5.3 If something surprising happens:

Suddenly, ...

Unexpectedly, ...

2.5.4 For the ending of the story:

Finally, ...

In the end, ...

Lastly, ...

\subsection{The Books}

The books came mostly from Cambridge University Press's "Cambridge English Readers" series. The complete series was available either as e-books directly from the teacher; or as hard copies available from the school's library.

Reading levels were established at first using the Shinshu level test. Those levels were used during the first half of the course. At the start of the second semester, students took Paul Nation's VST test. The Shinshy test focuses mostly on syntax and morphology; whereas the VST test is strictly a receptive vocabulary test. As a result, student scores were higher on the VST test than on the Shinshu test. Reading levels followed the Kyoto Scale, which is used on the MReader website.

\subsection{Students' Writing}

For this study, four students' work was randomly chosen from a total of fifteen students. For each of the chosen students, a further five summaries were randomly chosen from a total of eighteen summaries written throughout the school year. The summaries written in the second semester include a subjective writing section. The summaries exemplify the EVO method. In each case, the title of the book, along with the book's 'Kyoto level', are mentioned. Sequential markers are underlined throughout. Typos, misspellings and other grammatical errors were not edited.

\subsubsection{Student 1}

- Student 1 Summary 1 from Killer Bees (“A Car Ride”) (K5):

"In the beginning, Jo had a fight with her mom because Jo and her mother wanted to go out tomorrow. Then, no one could take care of Amy. Jo felt unhappy after she went to school. $\underline{A}$ few minutes later, Jo saw Mickey going by. They drove Jo's mom's car out to play. Unfortunately, Mickey drove car more and more fast. The car went off the road and into the woods. Finally, Jo called 911 and asked for help."

- Student 1 Summary 3 from A Picture to Remember ("An Accident in the Gym”) (K5): 


\section{MInstitute Macrothink $_{\text {Ins }}$}

"In the beginning, Cristina works in a gallery. One day, she waited for the traffic lights. She saw two men with a gun next door in the car. Then she was hit suddenly by a taxi car. When she woke up in the hospital, she lost the car accident and the memory of the two mysterious men. Finally, the two men feared she would recover. They decided to let her never remember."

- Student 1 Summary 8 from $\underline{\text { A Love for Life }}(\mathrm{K} 9)$ :

"In the beginning, Fanella wants to become a mother. However, doctor says she can't have children of her own. She and her husband decide to adopt. Unfortunately, Steven leaves Fanella to find another women. Fanella tells her best friend, Teresa this things. Timothy knows that Fanella wants a child. Finally, Teresa lets her son to call Fanella the second mother."

- Student 1 Summary 13 from Nelson's Dream (K9):

"In the beginning, Nelson Mbizi comes back to his hometown to help his father with his hotel business. Accidentally, he hears about Daniel and his tragic family story. Finally, he decides to help them and concerns a series of AIDS problems."

- Subjective Writing from Nelson's Dream (K9):

"The story is really touching, it make me fall in love with the characters. It shows the real effect AIDS has in people with little resources in Africa. If I have the opportunity to help someone I would help them. Because I don't know in which time I might need their to help me."

- Student 1 Summary 16 from Trumpet Voluntary (K9):

"In the beginning, Derek seek his girlfriend, Malgosia. However, one email let he know where is she. She is in Rio with Tibor, her first love. Therefore, he take a plane to contact with Osvaldo, a secret agent. While Osvaldo is searching, the police accused Derek because Malgosia was dead. Finally, everyone find that Tibor think he have the truth drug but it isn't. As a result, Tibor was arrested and Derek married with Rachel in the end."

- Subjective Writing from Trumpet Voluntary (K9):

"I like this book because it seems impossible to feel so happy and so sad at the same time. However, I want to beat up Tibor when I read this book, because he is a greedy, selfish, jealous man."

\subsubsection{Student 2}

- Student 2 Summary 1 from Ten Long Years (K4):

"In the beginning, Nat Marley gives his name card to Jorge Hernandez and then reads some of Jorge Hernandez's writing. Jorge Hernandez wants he to find Mike Lopez. Because of it Nat Marley calls Captain Oldenberg and find him. By the way, we learn that Pablo Rodriguez and Ramon Garcia are both dead after read an old news story from the Daily News website. Finally, Nat Marley is forced into Mark Lopez's car." 
- Student 2 Summary 4 from How to Stay Healthy (K4):

"In the beginning, we know our body needs exercise and the right food to stay healthy. Then, there is a new problem - many people eat too much and don't do much exercise. It's unhealthy. Besides, we need to drink about eight glasses of water every day. Exercise is good for you. It helps to make your bones and muscles stronger. Also, it protects you from health problem. Everyone needs to do exercise to stay healthy, it isn't only for young, healthy people. Older people and people with health problems or disabilities need exercise, too. Finally, it's important to rest. Most people need to sleep six and eight hours every night. Children need to sleep more than nine hours every night."

- Student 2 Summary 9 from A Dangerous Sky (K9):

"Francesca Bartolli calls her mother after her first lesson. Then, she meets Mrs. Barker and practices first landway. Remembering the manager of a café where she had worked. Getting her money back from Fastwings. At Flying Start, she meets Tom Brennan. Practicing her landing skills with George Scott. Finally, she goes solo for the first time and passes her private pilot's exams."

- Subjective Writing from A Dangerous Sky (K9):

"I think this book is positive. First time she didn't do well in flying, but finally she can landing successfully."

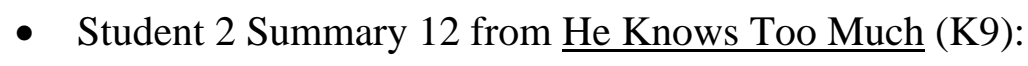

"The story begins in 1986 in Madras, a city of India. Dick works as a general manager in a multinational company. He discovered that Vish, the office manager of his company, took advantage of employees and of the company money. He called Keith and told him all that he knew. He went to Delhi for a meeting with his boss and was forced to take an early retirement. Dick and his family returned to Cambridge and he started to drink, had problems with his sons and wife. Finally, he was alone. Ramu was asking Dick for help. Dick decided to India for find out information about these early retirement. Finally, he discovered Molly and Keith has a child and didn't tell the truth to anyone."

- Subjective Writing from He Knows Too Much (K9):

"I like this book because I didn't guess the ending that Dick marries Lakshmi. Keith and Molly has a child when they were younger but he was married, and nobody knew this. It also surprised me. It's the reason why Keith can permit the corruption in his company. Finally, Dick didn't say the truth to anyone because that would ruined Keith's marriage. I think it is why the book is named "he knows too much." He discovers many thing but something he can't tell the others. Furthermore, maybe he didn't know these is better for him."

- Student 2 Summary 17 of The Best of Times (K9):

"Chee Sang sees his father in bed with another woman and he notices his mother's swollen eye. His dog dies at the side of the road. Then, he goes to Ka Ting's party and knows Jessica likes him because Ka Ting told him about this. In the party, Ka Ting gave Jessica the pills 
which make people feel better. Jessica takes it, but Chee Seng doesn't. After that the police come put everyone in jail. Chee Seng knew his mother in the hospital and he was afraid for his mother. He visits Jessica at the hospital. Finally, Jessica invited him to a party at her house and he gets a second dog for his seventeenth birthday."

- Subjective Writing for The Best of Times (K9):

“First time I didn't like this book because everything is awful. Chee Seng's family problem, betrayed friend, which tell the others about his family, his poor dog he loved very much, but it dies. He goes to Ka Ting's party, but the police put them in jail because Ka Ting gives pills to somebody. His mother is in the hospital and the situation is not good. Jessica is in the hospital, too. But when I read the chapter 15, I think everything is alright, and the story is not really bad. Chee Seng's father came back and his mother could be home by next week. He gets a second dog in his seventeenth birthday because his father sents him and his family loves him now. Jessica is fine. However, she almost died from the mixture of pills she took. Finally, she can leave the hospital and she is able to go home."

\subsubsection{Student 3}

\section{- Student 3 Summary 4 from Jojo's Story (K5):}

"At the start, Jojo's family are killed. They lie in their house with lots of blood. Second, Jojo finds Whitetail. Whitetail is a chicken he kept. Before long, Jojo leaves his village, and then on the way to Children's House. About a few hours afterwards, Jojo starts living in the Children's House. A few weeks later, Jojo meets his brother's friend. In the end, Jojo takes Duck's gun and boots and then he leaves Children's House with a friend of his brother."

- Student 3 Summary 7 from Bad Company (K5):

"At the outset, DI Helen Shepherd asks DS Brian Webb to get a waiter at the Grand Hotel.

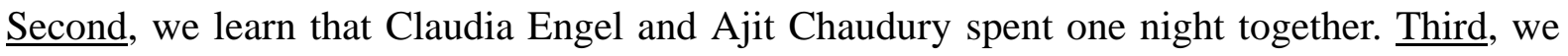
learn that Darran Fleming and Claudia Engel had studied together in London. After that, we learn the key to Claudia Engel's hotel room has disappeared. Finally, James McNab confesses to murdering Claudia Engel."

- Student 3 Summary 8 from Nelson's Dream (K9):

"In the beginning, Melanie died for terrible and horror AIDS. Second, Philomena asked Ruby to help Melanie's children. Third, Viki filmed Daniel and his siblings. Fourth, Eddy ran away. $\underline{\text { Fifth, }}$ the grocer found a rentor for the house. Sixth, Daniel got a job. After that, Phil filmed Daniel again. Finally, Kundai came to hear Daniel sing."

- Subjective Writing for Nelson's Dream (K9):

"I like this book. Because the plots are really touching. Especially Eddy's parents were died, and they became orphans from then on. It's really sorrowful to hear about people died for AIDS. AIDS is really a devil what stole many families happiness. I really feel happiest about my mother and my sisters don't have AIDS or any other diseases. I'm so lucky exactly." 
- Student 3 Summary 9 from Jungle Love (K8):

"At the outset, Jennifer picks a tour with Lisa. And then, Jennifer meets Ian and thinks him like a picture. After that, Lisa decides to hunt Ian necessarily. Afterwards, Pete phoned Jennifer to ask her to give him a call. Later, Ian kisses Jennifer at night of nights. Subsequent, Jennifer and Lisa quarrel with each other. Next, Jennifer and Lisa catch Ian unfaithful. Finally, Jennifer and Lisa become the best friends in the world."

Subjective Writing for Jungle Love (K8):

"I like this book. When I read it at the start, I thought maybe Jennifer will be with Ian finally. But to my surprise, Ian was an unfaithful man. He likes Jennifer and Lisa at the same time. He was really a bad bad man. Fortunately, Jennifer and Lisa saw what kind of person Ian is clearly. Finally they became the best friends. I really like this kind of ending."

- Student 3 Summary 10 from The Best of Times (K9):

"At the start, Chee Seng notices his mother's swollen eye. Afterwards, Chee Seng's father moves out of the house. And then, Chee Seng's mother gets a job. After that, Chee Seng's dog dies at the side of the road. Soon after, Ka Ting offers Chee Seng a ride home. Thereafter, Chee Seng finds out Jessica likes him. Seventh, Chee Seng's mother is upset and slaps him across the face. At last, Chee Seng is interrogated by a senior policement."

- Subjective Writing for The Best of Times (K9):

"Yes, I like this book, especially this book's ending. But there's still something I have to complain. What a big garbage Chee Seng's father is! How can he did such nasty, filthy, foul, repulsive, disgusting and really uncomfortable things to his family? I really nearly wanted to kill him while I read this book. How irresponsible for him to be a husband and a father! It's really not a pity that this kind of men die for one billion times! Even if he works extremely very hard for his wife and son still can't make up for a deficiency. And so does Chee Seng, he wanted to run away in that crazy way. What a stupid, silly, foolish, selfish, clumsy and annoying son he is! Moreover, he really couldn't empathize his mom after his father ran away and then his mom needed to work for this family. He just saw his own pain. He just tought about himself. The result is he let his mom cracked up. But finally he realized that what he all did are so stupid and selfish. He also realized that his mom is the most important in the world."

\subsubsection{Student 4}

- Student 4 Summary 2 from Jojo's Story (K5):

"At the start of the story, Jojo's family were killed by a man. After that, Jojo hid in the stable that he didn't want anyone to find out him. Suddenly, some soliders came to Jojo's village in a lorry. There is an English newspaper writer whose name is Chris helped Jojo. Jojo started living in the Children's House and there is a woman whose name is Doctor Nicky showed Jojo round the Children's House. After few weeks, the UN soldiers came back to the Children's House and Jojo saw Duck. Jojo sit by the wall and Duck's gun and boots are next 
to him. Very quickly, he picked up the big gun and the boots. In the end, Jojo and his brother's friend went through the house and left there."

- Student 4 Summary 5 from Dead Cold (K5):

"At the start of the story, Flick's boss told her there was a woman whose named is Janine Anderson been killed in Pine Crest and asked her to find out the murderer. The next day, Fick went to the hotel which Janine lived to visit her friend, Teresa and Jeff, and interviewed them. And then, Teresa told an important key about Janine - she always write down her everything in her notebook. When Flick wanted to find it, she found that it was missing. And the next day, Jeff came to find Flick to talk about the journalism competition. At the end of the story, Flick finally found the murderer who killed Janine."

\section{- Student 4 Summary 8 from The New Zealand File (K5):}

"In the beginning, Ian Moore got a phone call from Naylor who is his boss asked him to go to New Zealand as soon as possible. At the same day night, Munro arrived in New Zealand. He met Cochrane and got a car from him. When Munro was driving the car, he noticed that there is a car followed him. He drove quickly to leave that car and went to a beach to meet someone who gave Munro a code. But there was a man followed Munro. Munro needed to crack the code to deal all these situations and found out what happened."

- Student 4 Summary 12 from A Dangerous Sky (K9):

"At the start of the story, Francesca Bartolli was trying to let the plane flying into the air. After the lesson, Francesca got home and called her mother because her mother was worried her lessons. A few days later when Francesca finished lesson and needed to take bus to go home. But she found out that she missed the bus. So her teacher, Doug Barker gave her a lift back home. In the car, Francesca noticed Doug was asking about her private life. She felt uncomfortable but she couldn't do anything. When she got home, she was thinking about register the new flying school, Flying Start. Then, she decided to visit Flying Start. She meet George Scott there. After that her lessons with Flying Start went very well. However, she realizes that Doug is stalking her. He send her a text message which was designed to frighten her even more. But after few weeks, she heard the news that Fast Wings had gone out of business. This made Francesca felt more relaxed. In the end of that story, Francesca finally took her first cross-country flight. And realized her dream."

- Subjective Writing for A Dangerous Sky (K9):

"I like this book because it's very excited. And when I saw that Doug send a text message which was designed to frighten her. It was terrible!! But Francesca didn't afraid of him and realized her dream about her first cross-country flight!! It was great."

- Student 4 Summary 16 from Solo Saxophone (K9):

"At the start of the story, Kathy got a phone call from her boss, Caryl. Caryl asked to see Katy in her office. Caryl wanted Katy to go to Sarajevo to report on the war the Serbs, the Bosniaks and the Croats. After few weeks, Katy arrived at Sarajevo. The first thing she did 
was checked into her hotel in Sarajevo. She soon made friends with Carla Bosisio. They went to a café and saw Zeljko who is a saxophonist there. Few weeks passed, one day, Katy was shot by snipers and she saved by an old man who took her back to the hotel. Later still, Carla came to find her and told her about the deaths of the saxophone players. In the end, Katy was in a London hospital. The doctor said that Katy was pregnant. She also realizes that even in war, life and love go on."

- Subjective Writing for Solo Saxophone (K9):

"Yes, I did. And the most impressive paragraph for me is the mercenary called Jack Hickton who shot two little girls both dead. I'm so surprised because it's too cruel. I can't imagine that if this happened in the real life !!"

\section{General Assessment and Conclusion}

The student writing excerpts presented above exemplify the EVO method at work. In most cases, students can be seen improving their summarizing skills through a repetition of the general process.

The upshot is that students can develop summarizing skills, along with basic logical skills by engaging in simple book reading and quiz taking over a period of two semesters.

\section{References}

Cirocki, A. (Ed.) (2009). Extensive Reading in English Language Teaching. Muenchen: LinCom Europa.

Day, R. R. (2010). Bringing Extensive Reading into the Classroom. Oxford: Oxford University Press.

Ellis, R. (1994). Factors in the Incidental Acquisition of Second Language Vocabulary from Oral Input: A Review Essay. Applied Language Learning, 5, 1-32.

Gorsuch, G., Taguchi, E. (2009). Repeated Reading and Its Role in an Extensive Reading Programme. In Cirocki (2009), 249-271.

Holding, D. H. (Ed.) (1989). Human Skills. New York: John Wiley.

Krashen, S. (1982). Principles and Practice in Second Language Acquisition. Oxford: Pergamon.

Krashen, S. (1989). We Acquire Vocabulary and Spelling by Reading: Additional Evidence for the Input Hypothesis. Modern Language Journal, 73, 440-462. https://doi.org/10.1111/j.1540-4781.1989.tb05325.x

Krashen, S. (1997). The Comprehension Hypothesis: Recent Evidence. English Teachers' Journal (Israel), 51, 17-29. 
Krashen, S. (2007). Free Voluntary Web-surfing. The International Journal of Foreign Language Teaching, 3(1), 2-9.

Leow, R. P. (2009). Simplified Written Input and its Effects on L2 Comprehension: What the Research Reveals. In Cirocki (2009), 129-141.

Loucky, J. P. (2009). Enhancing Skills Essential for Effective Reading. In Cirocki (2009), 47-82.

MacAndrew, Richard (2011). Bad Company, Cambridge English Readers, Level 2, Cambridge University Press.

McLaughlin, B. (1987). Theories of Second Language Learning. London: Edward Arnold.

Nation, P. (2012). The Vocabulary Size Test, available online at http://www.victoria.ac.nz/lals/about/staff/publications/paul-nation/Vocabulary-Size-Test-infor mation-and-specifications.pdf

Newfields, T. (2001). Teaching Summarizing Skills: Some Practical Hints. ELJ Journal, 2(2), $1-7$.

Robb, T. (2010). A Digital Solution for Extensive Reading. In Day (2010), 105-110.

Robb, T., \& Kano, M. (2013). Effective Extensive Reading Outside the Classroom: A Large-scale Experiment. Reading in a Foreign Language, 25(2), 234-247.

\section{Copyright Disclaimer}

Copyright for this article is retained by the author(s), with first publication rights granted to the journal.

This is an open-access article distributed under the terms and conditions of the Creative Commons Attribution license (http://creativecommons.org/licenses/by/3.0/).

\footnotetext{
' In the present context, 'research writing' can be understood roughly to include any form of writing that typically derives from bibliographical sources. In this sense, anyone from undergraduate students to research fellows can fall within the category of 'research writer'. Research writing, as understood here, crucially depends on the ability to summarize what others have put forth in their own writing.

As an independent form of writing-which is the focus of this essay-summarizing skills can be introduced in the reading/writing class. I return to this understanding of summarizing in the next section.

ii Although typically text-based (books, articles, magazines, newspapers, etc. in either hard copy or electronic form) the source can also be audio-visual - a film, a TV documentary, a TV/radio program, etc.
} 
iii Cognitive theory holds that "the acquisition of a complex skill that begins as a controlled process [...] gradually becomes an automatic process through routinization, which requires less cognitive effort." Leow (2009, 130). See also McLaughlin (1987) and Holding (1989).

iv See Krashen (1982). I return to the notion of comprehensible input in a later section. In this context, it is important to distinguish between comprehensible and comprehended input, where the latter is the target goal. Simply put, the fact that input is comprehensible does not automatically imply that it is comprehended. Hence my insistence on 99 100\% comprehensible input, which gives readers the best chance of effectively acquiring new vocabulary. See Loucky (2009) and Ellis (1994).

` Several online 'level tests' are currently available. Publishers such as Macmillan, Penguin, Cambridge University Press and Oxford University Press have their own online reading level placement tests. Those tests offer a starting point, and students can then fine-tune their reading level further after experimenting with a few titles. Another, more recent online level test has been introduced by teachers at Shinshu University in Japan in October 2014. The Shinshu test uses several actual samples from English readers to determine a reader's reading level. The test includes three or four rounds, with each round leading to true/false questions and a 4-entry survey to fine-tune subsequent rounds if need be. The Shinshu test uses the 16-level scale used by ERF-the Extensive Reading Foundation. Hence the Shinshu test is referred to as "the ERF level test." Yet another resource is Paul Nation's "Vocabulary Size Test" (VST), also available online. The VST test scores provide the approximate number of receptive vocabulary items (headwords) known to the test taker, hence providing a guiding point of entry for graded readers. See Nation (2012). While all those online tests aim at helping students find the right reading level, it is of course always possible to find the right level by simply using book excerpts at various levels until one finds a comfort zone- the rule of thumb being to find the right reading level without using a dictionary or translation in the L1. This assures 100\% comprehensible input. Once they have found the right reading level, students are free to read any graded reader at that 'optimum' level. Again, it is crucial that students read books they understand when learning to summarize.

vi I return to confidence building and motivation in a later section.

vii This goes against the 'no pain no gain' philosophy often encountered in a typical 'cram school' or university language classroom. Students come to class with L1/L2 dictionaries and compile endless lists of vocabulary that they memorize in the hope of gaining fluency in the L2. The extensive reading (ER) method proposed here follows a different path towards fluency. The basic principle of ER is that students must acquire the structure of the L2 first, and this is done by repeated, sustained exposure to fully comprehensible input in the L2-i.e. by reading well-formed sentences in the context of books. This way, dictionary use is kept at a minimum. I return to this question in a later section.

viii The list of events is written in reported speech. See next section, where I provide an example.

ix This is a common feature of narratives. We all enjoy a good book or a good movie precisely when we can identify with a character or a given part of the plot. Aristotle called it 'catharsis' - the deep emotional connection experienced by the audience members - or readers, in the present context.

${ }^{x}$ This points to the need for a reading course taken in parallel to a writing course. Repetition is crucial. I will address this need in a later section on motivation.

\footnotetext{
${ }^{\text {xi }}$ See Newfields (2001).

xii See MacAndrew (2011).
} 
xiii The MReader online quiz bank is an excellent pedagogic tool that helps students sharpen their re-mapping skills. Essentially, MReader offers an EVO exercise with each quiz. Easily accessible online, it helps with student motivation. I will introduce MReader in a later section titled The Online Quiz Bank.

xiv There are essentially two different ways of understanding repeated reading (RR) in this context. One involves re-reading certain passages or sections of a book several times to gain fluency and comprehension, whereas the other involves the repeated action of reading several books one after the other over the course of a semester, say. For the benefits of re-reading certain sections of a book, see Gorsuch \& Taguchi (2009). In the present context, RR should be understood as the sustained reading of several books over the course of an entire semester.

${ }^{x v}$ See Krashen, ibid., with the proviso introduced in note 6 above - the distinction between comprehensible and comprehended input.

${ }^{x v i}$ Many writers have claimed over the years that 95-98\% comprehensible input is ideal for Extensive Reading. The problem with this approach is easy to state: $5 \%$ of a 30,000-word book-the typical word count of upper-level graded readers - comes to 1,500 words unknown to the reader. This means the student must spend so much time consulting a dictionary that the enjoyment of the reading gets lost and the entire activity loses its appeal. The prospect of having to go through the same ordeal 10 to 12 times over the course of a semester kills motivation in the bud. I insist on 99 100\%

comprehensible input as a starting point. This minimizes the occurrence of large amounts of unknown vocabulary and increases the likelihood of successfully guessing meaning from context with little, but productive, dictionary use and/or translation. Students fully understand the books they read and can concentrate on the summarizing tasks.

xvii See Krashen, ibid.

xviii Whereas such positive results are often criticized for being focused mainly on learners originating from Western cultures - and the implications this has for students of Asian cultures - we need not dwell on those problems here.

${ }^{x i x}$ The teacher is in firm control of the word goals and establishes the minimum needed to secure a passing grade in the course. The entire grading system is under the teacher's control.

${ }^{x x}$ This of course raises concerns about system security and the possibility of quiz-hacking and cheating. Those concerns should be addressed at length in a separate paper. I will say here, however, that online quiz banks can easily implement built-in trackers that log activities on the website and a "cheating alert" function. Red flags go up whenever two or more classmates take the same quiz over relatively short intervals, for example. It is then to the teacher's discretion whether to bring the matter up with the students. During a one-year period where a total of 600 students were registered quiz-takers, issues of cheating came up exactly four times. The freedom allowed students to choose from a very large pool of books minimises such instances.

${ }^{x \times i}$ The digital solution created at Kyoto Sangyo University - the MReader online quiz bank- has proven remarkably effective at helping both students and teachers. See <mreader.org >

xxii See Robb 2010, 2013.

xxiii As of this writing, MReader features approximately 5,000 quizzes for English graded readers from dozens of publishers. New quizzes are regularly written and uploaded on the website. The implementation proved a bit more complicated because of discrepancies between various publishers 
of graded readers in establishing the different reading levels. This eventually led to the establishment of the Kyoto Scale, whereby the several variations among reading levels from different publishing houses were normalized on a scale of 0 to 9 - there are 10 reading levels on the Kyoto scale, and all the quizzes currently available on the website are clearly identified by their unique Kyoto level. The Kyoto scale thus brings a smooth gradation scheme in what would otherwise be a rather chaotic and confusing environment for students.

xxiv See Krashen 1982. 